\title{
Perencana Pengembangan Industri di Propinsi Kalimantan Timur dengan menintegrasikan metode Location Quotient dan Analisis Bertingkat (Analytical Hierarchy Process)
}

\author{
Bambang Sutejo, Mohamad Koirul Amin, Sari \\ Jurusan Teknik Industri UNIPRA \\ Email : bamsitats@gmail.com
}

\begin{abstract}
ABTRAK
Kopetisi di dunia yang semakin ketat diera globalisasi dan perdagangan bebas APEC, mengharuskan pengembangan industri provinsi Kalimantan Timur, Industri di propinsi Kaltim terdapat kesenjangan wilayah yang cukup besar antara Pulau Jawa dan Luar Pulau Jawa, diantaranya dalam hal jumlah unit usaha industri besar dan sedang, kontribusi sektor industri non migas, investasi sektor industri PMA dan PMDN, serta luas lahan kawasan industri

Hasil perhitungan Location Quotient (LQ) Tahun 2016, maka secara rata-rata dapat diidentifikasikan sektorsektor yang merupakan sektor basis (nilai $L Q>1$ ) adalah sektor Pertambangan dan Penggalian (dengan sub sektor basis : Minyak dan Gas Bumi dan Pertambangan Tanpa Migas dengan nilai LQ masing-masing sebesar 3,81 dan 10,12) dengan nilai LQ keseluruhan 5,95. Sektor Pertambangan dan Penggalian merupakan sektor yang memiliki keunggulan sehingga mampu memenuhi kebutuhan di dalam Provinsi Kalimantan Timur serta mempunyai potensi untuk diekspor ke daerah di luar Kalimantan Timur. Sektor pertanian dan sektor pertambangan dan penggalian adalah sektor yang mampu menjadi sektor basis dominan di beberapa Kabupaten/Kota di Provinsi Kalimantan Timur.

Hasil analisis Klassen Tipology terhadap PDRB Provinsi Kalimantan Timur tahun 2015-2016 sektor yang dikategorikan sebagai sektor potensial, yaitu sektor yang mempunyai kontribusi rata-rata tinggi namun tertekan yaitu sektor "Pertam-bangan dan Penggalian" dan Industri Pengolahan. Pembangunan ekonomi dengan mengacu pada kedua sektor tersebut selain berdampak pada percepatan pertumbuhan ekonomi juga akan berpengaruh pada perubahan mendasar dalam struktur ekonomi. Sektor "Pertanian", "Listrik, Gas dan Air Bersih", "Bangunan", Perdag. Hotel dan Restoran”, Pengangkutan dan Komunikasi”, Keuangan Persewaan, dan Jasa Perusahaan”, dan "Jasa-Jasa" termasuk ke dalam sektor berkembang, Sementara sektor-sektor yang tergolong ke dalam sektor prima dan terbelakang tidak memiliki kontribusi dan nilai pertumbuhan
\end{abstract}

Kata Kunci : Sektor Basis, Location Quotient, Klassen Tipology, Pertumbuhan Ekonomi

\section{PENDAHULUAN}

\subsection{Latar Belakang Masalah}

Kebijakan Industri Nasional, Visi pembangunan Industri Nasional sebagaimana yang tercantum dalam Peraturan Presiden Nomor 28 Tahun 2008 tentang Kebijakan Industri Nasional adalah Indonesia menjadi Negara Industri Tangguh pada tahun 2025, dengan visi antara pada tahun 2020 sebagai Negara Industri Maju Baru, karena sesuai dengan Deklarasi Bogor tahun 1995 antar para kepala Negara APEC pada tahun tersebut liberalisasi di negara-negara APEC sudah harus terwujud.

Potensi Unggulan Daerah, dalam rangka pengembangan industri di Kalimantan Timur, dilakukan melalui pendekatan pengembangan komoditas, dan memperhatikan ragam komoditas yang dikembangkan, serta keterbatasan-keterbatasan dalam pengembangannya, maka komoditas-komoditas lebih lanjut diklasifikasi dalam 2 (dua) kategori, yaitu komoditas unggulan dan komoditas Fokus (potensial dan prospektif).

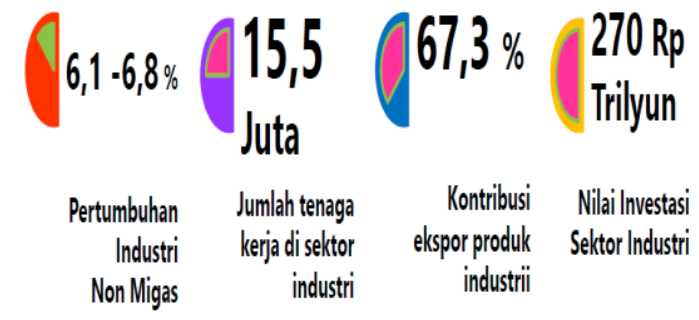

Sumber: Materi Presentasi Menteri

Perindustrian pada Raker Februari 2015

Gambar 1.1 Sasaran Pembangunan Industri Tahun 2015. 
Sasaran pembangunan industri pada tahun 2015 yang canangkan oleh Kementerian Perindustrian tampak dalam Gambar 1.2, dimana pertumbuhan industri non-migas tumbuh sekitar 6,1-6,8\%. Jumlah tenaga kerja yang terserap di sektor industri sebesar 15,5 juta. Kontribusi ekspor produk industri sebesar $67,3 \%$ dan nilai investasi PMDN dan PMA di sektor industri sebesar 270 trilyun rupiah.Sasaran pembangunan industri pada tahun 2015 yang canangkan oleh Kementerian Perindustrian tampak dalam Gambar 1.5, dimana pertumbuhan industri nonmigas tumbuh sekitar 6,1-6,8\%. Jumlah tenaga kerja yang terserap di sektor industri sebesar 15,5 juta. Kontribusi ekspor produk industri sebesar $67,3 \%$ dan nilai investasi PMDN dan PMA di sektor industri sebesar 270 trilyun rupiah.

Pada penelitian sebelumnya terkait rencana pengembangan industri,Akhmad Sutoni (2015) menggunakan metode LQ untuk melihat potensi sumber daya alam dan juga beberapa sektor berdasarkan PDRB, yang kemudian digunakan pendekatan logika Fuzzy untuk mendapatkan produk unggulan prioritas yang akan dijadikan kompetensi inti industri daerah kabupaten Kepulauan Sula dan diperoleh 10 kriteria prioritas diantaranya adalah ketersediaan \& kontinuitas bahan, dukungan sumberdaya manusia, aspekpemasaran, nilai tambah ekonomi, dukungan kebijakan dan kelembagaan pemerintah, nilaitambah sosial, kesiapan dan kesediaan masyarakat, kesiapan dan kesediaan pelaku usaha, danprestise daerah.

Pada penelitian rencana pengembangan industri provinsi Kalimantan Timur, peneliti mengamati terdapat kesenjangan wilayah yang cukup besar antara Pulau Jawa dan Luar Pulau Jawa, diantaranya dalam hal jumlah unit usaha industri besar dan sedang, kontribusi sektor industri non migas, investasi sektor industri PMA dan PMDN, serta luas lahan kawasan industri. Dengan adanya pengamatan terkait rencana pengembangan industri di provinsi Kalimantan Timur ini diharapkan dapat menggali potensi sumber daya industri daerah.

\subsection{Rumusan Masalah}

Berdasarkan latar belakang yang telah disusun maka rumusan permasalahan yang akan diselesaikan pada penelitian ini adalah sebagai berikut:

1. Bagaimana potensi sumber daya industri daerah provinsi KALTIM?

2. Apa Sektor perekonomian yang menjadi sektor basis provinsi KALTIM?

3. Bagaimana pertumbuhan dan kontribusi sektor tertentu terhadap total PDRB di provinsi KALTIM menurut Tipology Klassen?

\subsection{Tujuan Penelitian}

Berdasarkan rumusan permasalahan yang akan diselesaikan, maka tujuan yang diharapkan dengan adanya penelitian ini adalah sebagai berikut:

1. Menentukanpotensi sumber daya industri daerah provinsi KALTIM.

2. Menentukan sektor basis provinsi KALTIM.

3. Menentukanpertumbuhan dan kontribusi sektor tertentu terhadap total PDRB di provinsi KALTIM menurut Tipology Klassen.

\section{LANDASAN TEORI}

\subsection{Analisis Location Quotient (LQ)}

Di dalam model ekonomi basis, perekonomian terbagi menjadi dua yaitu sektor basis dan non basis. Sektor basis disebut juga sektor ekspor dan akan menentukan perkembangan wilayah. Kedua sektor memiliki hubungan, dimana jika sektor basis berkembang, maka pada gilirannya akan meningkatkan pula kegiatan non basis. Hal inisering disebut dengan multiplier effect. Untuk mengetahui sektor basis dan non basis digunakan metode analisa Location Quotient (LQ). Analisis LQ (Location Quotient) adalah suatu metode yang digunakan untuk mengetahui tingkat spesialisasi dan mengindikasikan sektor basis atau leading sector (warpani, 2001).

$$
L Q_{t}=\frac{\left(S_{i j} / S_{i}\right)}{\left(\sum S_{j} / \sum S\right)}
$$

$\mathrm{Sij}=$ Sektor i pada daerah $\mathrm{j}$

$\mathrm{Si}=$ Total produksi sektor $\mathrm{i}$

$\mathrm{Sj}=$ Total produksi pada daerah $\mathrm{j}$

$\mathrm{S}=$ Total produksi seluruh daerah 
Terdapat tiga golongan nilai dari Location Quotient (LQ), yaitu sebagai berikut :

1) Jika LQ $>1$ maka mengindikasikan bahwa suatu wilayah mempunyai spesialisasi yang tinggi (basis).

2) Jika LQ < 1, maka mengindikasikan bahwa suatu wilayah mempunyai spesialisasi yang rendah (non basis).

3) Jika $\mathrm{LQ}=1$, maka mengindikasikan bahwa suatu wilayah mengalami self sufficient (spesialisasi sama).

\subsection{Analisis Klassen}

Metode Klassen mendasarkan pengelompokkan suatu sektor dengan melihat pertumbuhan dan kontribusi sektor tertentu terhadap total PDRB suatu daerah (Sjafrizal, 2008:180). Dengan menggunakan analisis tipologi Klassen, suatu sektor dapat dikelompokkan ke dalam 4 kategori, yaitu:

a. Sektor Prima

b. Sektor Maju, tetapi tertekan (sektor Potensial).

c. Sektor Berkembang, dan

d. Sektor Terbelakang

Penentuan kategori suatu sektor ke dalam empat kategori di atas didasarkan pada laju pertumbuhan kontribusi sektoralnya dan rerata besar kontribusi sektoralnya terhadap PDRB, seperti yang ditunjukkan pada gambar matriks berikut.

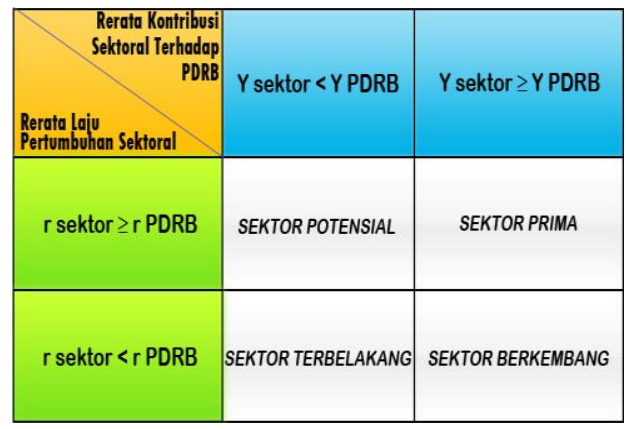

Gambar 2.1 Analisa Klasen Sektor Ekonomi

\subsection{Analisis Gravitasi}

Analisis ini digunakan untuk mengetahui kemampuan mengakses yang diharapkan terjadi antar wilayah kota kabupaten di wilayah Provinsi Kalimantan Timur. Adanya interaksi wilayah 1 dengan wilayah 2 menunjukkan eratnya hubungan antara kedua wilayah tersebut. Analisis ini juga digunakanuntuk mengetahui kemampuan aksesibilitas kota kabupaten di wilayah Provinsi Kalimantan Timur terhadap Kota Samarinda sebagai pusat ibukotaProvinsi sekaligus sebagai kota pusat pertumbuhan di Kota. Model Analisis Gravitas dapat ditulis sebagai berikut (Tarigan,2006)

$$
A_{i j}=\frac{P_{i} P_{j}}{d^{2}{ }_{i j}}
$$

Aij $=$ Tingkat aksesibilitas lokasi ke $\mathrm{j}$

$\mathrm{Pi} \quad=$ Aspek yang diukur di lokasi i (dalam hal ini jumlah penduduk di wilayah i).

$\mathrm{Pj} \quad$ = Aspek yang diukur di lokasi $\mathrm{j}$ (dalam hal ini jumlah penduduk di wilayah $\mathrm{j}$ ).

dij = Faktor yang mempengaruhi (dalam hal ini digunakan jarak tempuh dari kota/kabupaten I ke kota/kabupaten j).

\subsubsection{Proses Analisis Bertingkat (Analytical Hierarchy Process)}

Analisis terhadap keseluruhan data yang dihimpun dilakukan berdasar variabel yang ditetapkan; untuk menentukan jenis potensi investasi/potensi unggulan daerah yang cukup feasible dikembangkan. Masing-masing potensi unggulan dianalisis dengan metode Analytical Hierarchy Process.

Proses penetapannya adalah dengan memperbandingkan indikator satu dengan yang lain dengan metode Dunn-Rankin's Variance Stable Rank Sum untuk mendapatkan nilai bobot antar indikator.

Proses pembobotan ini didasarkan pada masukan dari para ahli di bidang penanaman modal dan pengusaha. Dasar penilaian tiap faktor tersebut didasarkan dengan metode DunnRankin's Variance Stable Rank Sums yang menggunakan kuisoner I. Masing-masing indikator diberi bobot nilai $1 \mathrm{~s} / \mathrm{d} 4$ yang artinya yaitu :

1. (sangat tidak potensial)

2. (tidak potensial)

3. (potensial)

4. (sangat potensial).

Dari predikat yang dimiliki kemudian akan dinilai dengan cara mengalikan nilai masing-masing indikator dengan bobot kriteria tersebut. Sebelum dilakukan penilaian dilaku- 
kan pembobotan terlebih dahulu terhadap indikator - indikator yang ada. Bobot masing masing predikat tersebut akan dikalikan dengan nilai dari indikator-indikator tersebut menggunakan data ordinal $1 \mathrm{~s} / \mathrm{d} 4$, dengan bobot penilaian yang berbeda untuk masing-masing indikator :

\subsection{Analisis Spasial}

Analisa ini dilakukan dengan meninjau arahan kebijakan yang terdapat pada RTRW Kalimantan Timur . Sehingga diharapkan dapat dilakukan pemetaan yang tepat sasaran dan sesuai dengan arah kebijakan daerah yang telah dirumuskan sebelumnya. Terutama dalam meninjau kesesuaian wilyah antara kondisi eksisting dengan peruntukkannya di dalam RTRW yang ada.

\subsection{Profil Industri Provinsi Kalimantan Timur}

Berdasarkan data paparan Kepala Disperindagkop Provinsi Kalimantan Timur dalam Rakor Bapeda se Kalimantan Timur 2015, diketahui data Kompetensi Inti Industri Daerah (KIID) Kalimantan Timur untuk Kota Samarinda yang masih dalam proses penyusunan Permenperin adalah industri tenun. Berdasarkan data Disperindakop \& UMKM Provinsi Kalimantan Timur, Komoditas Unggulan di Kota Samarinda adalah sebagai berikut: Perikanan, Pariwisata, Lada, Sarung Tenun, Batik,Batubara

Penggolongan sektor industri berdasarkan jumlah tenaga kerjanya dibedakan menjadi industri besar, industri sedang, industri kecil dan industri kerajinan rumah tangga. Data mengenai industri besar dan sedang tersedia setiap tahun, sedangkan data mengenai industri kecil dan rumah tangga tidak tersedia pada publikasi ini. Perusahaan industri besar merupakan usaha industri dengan tenaga kerja lebih dari 100 orang, dan industri sedang adalah usaha industri dengan tenaga kerja antara 20-99 orang. Banyaknya perusahaan Industri Besar dan Sedang di Kalimantan Timur pada tahun 2012. tercatat 129 perusahaan dengan menyerap 31.965 tenaga kerja, dengan total pengeluaran untuk tenaga kerja berkisar $\mathrm{Rp} 1,41$ triliun. Dilihat dari jumlah perusahaan, pada tahun 2012 mengalami peningkatan di-banding tahun 2011, dan penyerapan tenaga kerja serta nilai tambahnya juga meningkat sehingga pertumbuhan untuk sektor industri mengalami percepatan.

\section{METODOLOGI PENELITIAN}

\subsection{Metode Pengumpulan Data}

Data yang diperlukan dalam kajian ini adalah data primer dan data sekunder. Adapun data primer yang dibutuhkan diantaranya adalah:

1. Tanggapan responden pelaku industri terhadap pertanyaan-pertanyaan kualitatif penelitian.

2. Jawaban responden terhadap pooling menggunakan kuesioner dengan pertanyaan pilihan (closed-end).

Data sekunder dibutuhkan baik pada analisa aspek empiris maupun teoritis, diantaranya adalah:

1. Dokumen berupa produk kebijakan di bidang Perindustrian, baik produk kebijakan Kabupaten/ Kota, Provinsi maupun Nasional.

2. Data yang telah dikumpulkan dan ditabulasi oleh pihak lain, misalnya: BPS, SKPD, asosiasi, dan lain-lain.

\subsection{Metode Analisa Data}

Data primer dan sekunder yang telah terkumpul kemudian dianalisa agar bisa menjadi informasi yang berguna dalam pengambilan keputusan atau penyusunan kebijakan. Beberapa metode analisa data yang dapat diterapkan dalam kajian ini, diantaranya adalah:

1. Analisa data kuantitatif
a) Analisa deskriptif
b) Analisa kesenjangan
c) Analisa kuadran kepentingan dan kinerja
d) Analisa SWOT

2. Analisa data kualitatif

a) Analisa dengan teknik Miles Huberman

1) Reduksi data

2) Penyajian data

3) Penarikan kesimpulan

4) Verifikasi temuan penelitian

b) Analisa dengan teknik Strauss \& Corbin (open coding, axial coding, selective coding dan developing \& drawing a visual conditional matrix) 


\section{ANALISA DAN PEMBAHASAN}

\subsection{Profil Daerah Provinsi Kalimantan Timur}

Provinsi Kalimantan Timur merupakan salah satu Provinsi terluas kedua setelah Papua, memiliki potensi sumberdaya alam melimpah dimana sebagian besar potensi tersebut belum dimanfaatkan secara optimal. Sumberdaya alam dan hasil-hasilnya sebagian besar dieksport keluar negeri, sehingga Provinsi ini merupakan penghasil devisa utama bagi negara, khususnya dari sektor Pertambangan, Kehutanan dan hasil lainnya.

Secara administratif Provinsi ini memiliki batas wilayah sebelah Utara berbatasan dengan Kalimantan Utara, sebelah Timur berbatasan dengan sebagian (12 Mil) Selat Makasar dan Laut Sulawesi, sebelah Selatan berbatasan dengan Provinsi Kalimantan Selatan, sebelah Barat berbatasan dengan Provinsi Kalimantan Tengah dan Provinsi Kalimantan Barat serta Negara Bagian Serawak Malaysia Timur.

Kalimantan Timur memiliki luas wilayah daratan 127.267,52 km2 dan luas pengelolaan laut $25.656 \mathrm{~km} 2$ terletak antara $113^{\circ} 44^{\prime}$ Bujur Timur dan $119^{\circ} 00^{\prime}$ Bujur Timur serta diantara $2^{\circ} 33^{\prime}$ Lintang Utara dan $2^{\circ} 25^{\prime}$ Lintang Selatan.

\subsection{Profil Perindustrian Provinsi Kalimantan Timur}

Penggolongan sektor industri berdasarkan jumlah tenaga kerjanya dibedakan menjadi industri besar, industri sedang, industri kecil dan industri kerajinan rumah tangga. Data mengenai industri besar dan sedang tersedia setiap tahun, sedangkan data mengenai industri kecil dan rumah tangga tidak tersedia pada publikasi ini. Perusahaanindustri besar merupakan usaha industri dengan tenaga kerja lebih dari 100 orang, dan industri sedang adalah usaha industri dengan tenaga kerja antara 20-99 orang. Banyaknya perusahaan Industri Besar dan Sedang di Kalimantan Timur pada tahun 2016 tercatat 129 perusahaan dengan menyerap 31.965 tenaga kerja, dengan total pengeluaran untuk tenaga kerja berkisar $\mathrm{Rp}$ 1,41 triliun. Berikut merupakan data keadaan industri di Kabupaten/Kota di provinsi Kalimantan Timur terkait Kompetensi Inti Industri Daerah (KIID) dan komuditas unggulan bersarkan data paparan Kepala Disperindagkop Provinsi Kalimantan
Timur dalam Rakor Bapeda se-Kalimantan Timur 2015 adalah sebagai berikut

Tabel 4. Kompetensi Inti Industri Daerah (KIID) dan Komuditas Unggulan Kabupaten/Kota Provinsi Kalimantan Timur 1

\begin{tabular}{|c|c|c|}
\hline $\begin{array}{l}\text { Kota/ } \\
\text { Kabupaten }\end{array}$ & $\begin{array}{l}\text { Kompetensi Inti } \\
\text { Industri Daerah }\end{array}$ & $\begin{array}{l}\text { Komuditas } \\
\text { Unggulan }\end{array}$ \\
\hline Samarinda & Industri Tenun & $\begin{array}{l}\text { Perikanan, } \\
\text { Pariwisata, } \\
\text { Lada, Sarung } \\
\text { Tenun, Batik, } \\
\text { Batubara }\end{array}$ \\
\hline Balikpapan & $\begin{array}{l}\text { Industri produk } \\
\text { pengolahan ikan }\end{array}$ & $\begin{array}{l}\text { Perikanan, } \\
\text { Pariwisata, } \\
\text { Penggilingan, } \\
\text { Minyak Bumi }\end{array}$ \\
\hline Bontang & $\begin{array}{ll}\text { Indutri } & \text { produk } \\
\text { olahan } & \text { rumput } \\
\text { Laut } & \end{array}$ & $\begin{array}{l}\text { Perikanan, } \\
\text { Pupuk,LNG }\end{array}$ \\
\hline $\begin{array}{l}\text { Kutai } \\
\text { Kartanegara }\end{array}$ & $\begin{array}{l}\text { Industri } \\
\text { pengolahan } \\
\text { singkong } \\
\text { menjadi } \\
\text { bioethanol }\end{array}$ & $\begin{array}{l}\text { Kelapa Sawit, } \\
\text { Karet,Padi,Lad } \\
\text { a, Pisang, } \\
\text { Nanas, } \\
\text { Perikanan, } \\
\text { Pariwisata, } \\
\text { Batubara, HTI, } \\
\text { Gas }\end{array}$ \\
\hline Kutai Timur & & $\begin{array}{l}\text { Kelapa Sawit, } \\
\text { Jagung, } \\
\text { Pisang, Karet, } \\
\text { Batubara, HTI }\end{array}$ \\
\hline Berau & $\begin{array}{l}\text { Industri produk } \\
\text { pengolahan ikan }\end{array}$ & $\begin{array}{l}\text { Kelapa Sawit, } \\
\text { Terasi, Karet, } \\
\text { Padi, Kedelai, } \\
\text { Perikanan, } \\
\text { Kelapa, } \\
\text { Pariwisata, } \\
\text { Batubara }\end{array}$ \\
\hline $\begin{array}{l}\text { Penajam } \\
\text { Paser Utara }\end{array}$ & $\begin{array}{l}\text { Industri gula } \\
\text { merah }\end{array}$ & $\begin{array}{l}\text { Kelapa Sawit, } \\
\text { Durian, Karet, } \\
\text { HTI }\end{array}$ \\
\hline Paser & & $\begin{array}{l}\text { Kelapa Sawit, } \\
\text { Karet, Padi, } \\
\text { Pisang, } \\
\text { Perikanan, } \\
\text { Batubara, HTI }\end{array}$ \\
\hline Kutai Barat & & $\begin{array}{l}\text { Kelapa Sawit, } \\
\text { Karet, Durian, } \\
\text { Rambutan, }\end{array}$ \\
\hline
\end{tabular}




\begin{tabular}{|l|l|l|}
\hline & & Perikanan \\
& & Darat, \\
& & Batubara, \\
& & Emas \\
\hline & & \\
\hline
\end{tabular}

\subsubsection{Analisis Location Quotient (LQ) Provinsi Kalimantan Timur}

Analisis LQ digunakan untuk melihat sektor-sektor di Provinsi Kalimantan Timur yang memiliki peran wilayah yang besar serta prospektif untuk dikembangkan. Penghitungan LQ ini menggunakan data PDRB yang terdiri dari sembilan sektor/ lapangan usaha berdasarkan harga konstan yang dibandingkan dengan data PDB Nasional pada tahun 2016. Data PDRB Provinsi Kalimantan Timur dan PDB Nasional Tahun 2016 berdasarkan harga konstan 2000 dapat dilihat pada Tabel di bawah ini.

Tabel 4.2PDRB Provinsi Kalimantan Timur dan PDB Nasional Atas Dasar Harga Konstan 2000 Menurut Lapangan Usaha Tahun 2016 (Juta Rupiah)

\begin{tabular}{|c|c|c|}
\hline \multirow{2}{*}{$\begin{array}{c}\text { LAPANGAN } \\
\text { USAHA }\end{array}$} & JUMLAH & \\
\hline & $\begin{array}{r}\text { PDRB } \\
\text { KALTIM }\end{array}$ & $\begin{array}{r}\text { PDB } \\
\text { NASIONA } \\
\mathrm{L}\end{array}$ \\
\hline (1) & (2) & (3) \\
\hline 1. PERTANIAN & 8.664 .167 & $\begin{array}{r}339.890 .20 \\
0\end{array}$ \\
\hline $\begin{array}{l}\text { a. Tanaman Bahan } \\
\text { Makanan }\end{array}$ & 1.459 .667 & $\begin{array}{r}161.969 .50 \\
0\end{array}$ \\
\hline $\begin{array}{l}\text { b. Tanaman } \\
\text { Perkebunan }\end{array}$ & 1.854 .469 & 54.903 .000 \\
\hline $\begin{array}{l}\text { c. Peternakan } \\
\text { dan Hasil- } \\
\text { hasilnya }\end{array}$ & 969.778 & 43.914 .000 \\
\hline d. Kehutanan & 1.794 .891 & 17.442 .500 \\
\hline e. Perikanan & 2.585 .362 & 61.661 .200 \\
\hline $\begin{array}{l}\text { 2. } \\
\text { PERTAMB } \\
\text { ANGAN \& } \\
\text { PENGGALIAN }\end{array}$ & 51.237.177 & $\begin{array}{r}195.708 .50 \\
0\end{array}$ \\
\hline a. Minyak dan & 14.906 .500 & 88.741 .700 \\
\hline
\end{tabular}

\begin{tabular}{|c|c|c|}
\hline Gas Bumi & & \\
\hline $\begin{array}{l}\text { b. Pertambangan } \\
\text { tanpa Migas }\end{array}$ & 35.411 .565 & 79.470 .000 \\
\hline c. Penggalian & 919.112 & 27.496 .800 \\
\hline $\begin{array}{l}\text { 3. INDUSTRI } \\
\text { PENGOLAHAN }\end{array}$ & 26.232.254 & $\begin{array}{r}707.457 .80 \\
0\end{array}$ \\
\hline $\begin{array}{l}\text { a. Industri } \\
\text { Migas }\end{array}$ & 19.223 .522 & 44.627 .400 \\
\hline $\begin{array}{l}\text { 1. } \\
\text { Peng } \\
\text { ilangan } \\
\text { Minyak } \\
\text { Bumi }\end{array}$ & 4.588 .524 & 21.262 .600 \\
\hline $\begin{array}{l}\text { 2. Gas Alam } \\
\text { Cair }\end{array}$ & 14.634 .997 & 23.364 .800 \\
\hline $\begin{array}{l}\text { b. Industri } \\
\text { Tanpa Migas }\end{array}$ & 7.008 .732 & $\begin{array}{r}662.830 .40 \\
0\end{array}$ \\
\hline $\begin{array}{l}\text { 1. Makanan, } \\
\text { Minuman } \\
\text { dan } \\
\text { Tembaka } \\
\text { u }\end{array}$ & 1.215 .732 & $\begin{array}{r}194.063 .00 \\
0\end{array}$ \\
\hline $\begin{array}{l}\text { 2. Tekstil, } \\
\text { Brg. Kulit } \\
\text { \& Alas } \\
\text { kaki }\end{array}$ & 36.224 & 62.076 .700 \\
\hline $\begin{array}{l}\text { 3. Brg. Kayu } \\
\text { \& Hasil } \\
\text { Hutan } \\
\text { lainnya }\end{array}$ & 842.135 & 19.980 .800 \\
\hline $\begin{array}{ll}\text { 4. Kertas } \\
\text { dan } \\
\text { Barang } \\
\text { Cetakan }\end{array}$ & 2.488 .676 & 27.786 .100 \\
\hline $\begin{array}{l}\text { 5. Pupuk, } \\
\text { Kimia \& } \\
\text { Brg. dari } \\
\text { Karet }\end{array}$ & 2.043 .885 & 85.449 .300 \\
\hline $\begin{array}{l}\text { 6. Semen \& } \\
\text { Brg. } \\
\text { Galian } \\
\text { bukan } \\
\text { logam }\end{array}$ & 129.414 & 19.346 .500 \\
\hline $\begin{array}{l}\text { 7. Logam } \\
\text { Dasar }\end{array}$ & - & 10.091 .100 \\
\hline
\end{tabular}

Jurusan Teknik Industri Fakultas Teknik Industri UPN “Veteran” Yogyakarta 


\begin{tabular}{|c|c|c|}
\hline $\begin{array}{l}\text { Besi \& } \\
\text { Baja }\end{array}$ & & \\
\hline $\begin{array}{l}\text { 8. Alat } \\
\text { Angk., } \\
\text { Mesin \& } \\
\text { Peralatan } \\
\text { nya }\end{array}$ & 166.587 & $\begin{array}{r}240.031 .60 \\
0\end{array}$ \\
\hline $\begin{array}{l}\text { 9. Barang } \\
\text { lainnya }\end{array}$ & 86.079 & 4.005 .300 \\
\hline $\begin{array}{l}\text { 4. LISTRIK, GAS } \\
\text { \& AIR BERSIH }\end{array}$ & 457.314 & 21.201.000 \\
\hline a. Listrik & 400.067 & 13.952 .400 \\
\hline b. Gas & - & 4.763 .700 \\
\hline c. Air Bersih & 57.247 & 2.484 .900 \\
\hline 5. BANGUNAN & 6.053.293 & $\begin{array}{r}182.117 .90 \\
0\end{array}$ \\
\hline $\begin{array}{l}6 . \\
\text { PERDAGA } \\
\text { NGAN, HOTEL } \\
\text { \& RESTORAN }\end{array}$ & 12.502 .437 & $\begin{array}{r}501.158 .40 \\
0\end{array}$ \\
\hline $\begin{array}{l}\text { a. Perdagangan } \\
\text { Besar \& } \\
\text { Eceran }\end{array}$ & 11.150 .025 & $\begin{array}{r}419.458 .00 \\
0\end{array}$ \\
\hline b. Hotel & 309.934 & 21.232 .400 \\
\hline c. Restoran & 1.042 .478 & 60.468 .000 \\
\hline $\begin{array}{l}7 . \\
\quad \text { PENGANG } \\
\text { KUTAN \& } \\
\text { KOMUNIKASI }\end{array}$ & 8.487.588 & $\begin{array}{r}292.421 .50 \\
0\end{array}$ \\
\hline a. Pengangkutan & 6.978 .588 & $\begin{array}{r}104.787 .70 \\
0\end{array}$ \\
\hline $\begin{array}{l}\text { 1. Angkutan } \\
\text { Rel }\end{array}$ & - & 765.700 \\
\hline $\begin{array}{l}\text { 2. Angkutan } \\
\text { Jalan } \\
\text { Raya }\end{array}$ & 1.797 .159 & 44.282 .600 \\
\hline $\begin{array}{l}\text { 3. Angkutan } \\
\text { Laut }\end{array}$ & 714.330 & 10.128 .900 \\
\hline $\begin{array}{ll}\text { 4. Angk. } & \text { Sungai, } \\
\text { Danau \& } \\
\text { Penyebr. }\end{array}$ & 743.369 & 3.518 .100 \\
\hline $\begin{array}{l}\text { 5. Angkutan } \\
\text { Udara }\end{array}$ & 1.063 .231 & 22.701 .300 \\
\hline
\end{tabular}

\begin{tabular}{|c|c|c|}
\hline $\begin{array}{l}\text { 6. Jasa } \\
\text { Penunjan } \\
\text { g } \\
\text { Angkutan }\end{array}$ & 2.660 .500 & 23.391 .100 \\
\hline b. Komunikasi & 1.509 .000 & $\begin{array}{r}187.633 .80 \\
0\end{array}$ \\
\hline $\begin{array}{l}\text { 8. KEUANGAN, } \\
\text { PERSEWAAN, } \\
\text { \& JS. PRSH. }\end{array}$ & 5.300 .571 & $\begin{array}{r}272.151 .90 \\
0\end{array}$ \\
\hline a. Bank & 2.075 .776 & 113.983 .60 \\
\hline $\begin{array}{l}\text { b. Lembaga } \\
\text { Keuangan } \\
\text { tanpa Bank }\end{array}$ & 186.505 & 23.780 .500 \\
\hline $\begin{array}{l}\text { c. Jasa } \\
\text { Penunjang } \\
\text { Keuangan }\end{array}$ & 1.665 & 1.817 .300 \\
\hline $\begin{array}{l}\text { d. Sewa } \\
\text { Bangunan }\end{array}$ & 1.871 .085 & 80.684 .700 \\
\hline $\begin{array}{l}\text { e. Jasa } \\
\text { Perusahaan }\end{array}$ & 1.165 .540 & 51.885 .800 \\
\hline 9. JASA-JASA & 3.055.685 & 258.237.90 \\
\hline $\begin{array}{l}\text { a. Pemerintahan } \\
\text { Umum }\end{array}$ & 2.342 .256 & $\begin{array}{r}101.031 .80 \\
0\end{array}$ \\
\hline $\begin{array}{l}\text { 1. Adm. } \\
\text { Pemerinta } \\
\text { han \& } \\
\text { Pertahana } \\
\text { n }\end{array}$ & - & 63.407 .200 \\
\hline $\begin{array}{l}\text { 2. Jasa } \\
\text { Pemerinta } \\
\text { h lainnya }\end{array}$ & - & 37.624 .600 \\
\hline b. Swasta & 713.429 & 157.206 .10 \\
\hline $\begin{array}{l}\text { 1. Sosial } \\
\text { Kemasyar } \\
\text { akatan }\end{array}$ & 166.626 & 38.898 .200 \\
\hline $\begin{array}{l}\text { 2. Hiburan } \\
\& \\
\text { Rekreasi }\end{array}$ & 36.311 & 12.237 .500 \\
\hline $\begin{array}{l}\text { Pero } \\
\text { rangan \& } \\
\text { Rumahtan }\end{array}$ & 510.493 & $\begin{array}{r}106.070 .40 \\
0\end{array}$ \\
\hline
\end{tabular}

Jurusan Teknik Industri Fakultas Teknik Industri UPN “Veteran” Yogyakarta 


\begin{tabular}{|l|r|r|}
\hline \multicolumn{1}{|c|}{ gga } & & \\
\hline PRODUK & $\mathbf{1 2 1 . 9 9 0 . 4 8}$ & $\mathbf{2 . 7 7 0 . 3 4 5 . 1}$ \\
DOMESTIK & $\mathbf{6}$ & $\mathbf{0 0}$ \\
REGIONAL & & \\
BRUTO & & \\
\hline
\end{tabular}

Sumber : PDRB Provinsi Kalimantan Timur dan PDB Nasional Tahun 2015-2016, Data diolah

Logika dasar LQ adalah teori basis ekonomi yang intinya industri basis menghasilkan barang-barang dan jasa untuk pasar di daerah maupun di luar daerah yang bersangkutan, maka penjualan keluar daerah akan menghasilkan pendapatan bagi daerah tersebut. Kenaikan permintaan ini akan mendorong kenaikan investasi pada industri yang bersangkutan dan juga industri lainnya. Dengan demikian, keberadaan sektor basis tidak terlepas dari pengaruh sektor non basis dan sebaliknya, sektor basis dapat mempengaruhi sektor non basis.

Tabel 4.3LQ PDRB Provinsi Kalimantan Timur Menurut Lapangan Usaha Tahun 2016

\begin{tabular}{|c|c|c|}
\hline \multirow{2}{*}{ LAPANGAN USAHA } & LQ & \multicolumn{1}{|c|}{$(1)$} \\
\cline { 2 - 2 } & NILAI & KRITERIA \\
\hline 1. PERTANIAN & $(2)$ & $(3)$ \\
\hline $\begin{array}{l}\text { a. Tanaman Bahan } \\
\text { Makanan }\end{array}$ & 0,20 & Non Basis \\
\hline $\begin{array}{l}\text { b. Tanaman } \\
\text { Perkebunan }\end{array}$ & 0,77 & Non Basis \\
\hline $\begin{array}{l}\text { c. Peternakan dan } \\
\text { Hasil-hasilnya }\end{array}$ & 0,50 & Non Basis \\
\hline d. Kehutanan & 2,34 & Basis \\
\hline e. Perikanan & 0,95 & Non Basis \\
\hline $\begin{array}{l}\text { PERTAMBANGAN } \\
\text { a. Minyak dan Gas } \\
\text { Bumi }\end{array}$ & $\mathbf{5 , 9 5}$ & Basis \\
\hline $\begin{array}{l}\text { b. Pertambangan } \\
\text { tanpa Migas }\end{array}$ & 10,12 & Basis \\
\hline $\begin{array}{l}\text { c. Penggalian } \\
\text { 3. INDUSTRI } \\
\text { PENGOLAHAN }\end{array}$ & 0,76 & Non Basis \\
\hline
\end{tabular}




\begin{tabular}{|c|c|c|}
\hline $\begin{array}{l}\text { a. Perdagangan } \\
\text { Besar \& Eceran }\end{array}$ & 0,60 & Non Basis \\
\hline b. Hotel & 0,33 & Non Basis \\
\hline c. Restoran & 0,39 & Non Basis \\
\hline $\begin{array}{l}\text { 7. PENGANGKUTAN } \\
\& \text { KOMUNIKASI }\end{array}$ & 0,66 & Non Basis \\
\hline a. Pengangkutan & 1,51 & Basis \\
\hline $\begin{array}{l}\text { 1. Angkutan } \\
\text { Rel }\end{array}$ & 0,00 & Non Basis \\
\hline $\begin{array}{ll}\text { 2. Angkutan } \\
\text { Jalan Raya }\end{array}$ & 0,92 & Non Basis \\
\hline $\begin{array}{l}\text { 3. Angkutan } \\
\text { Laut }\end{array}$ & 1,60 & Basis \\
\hline $\begin{array}{l}\text { 4. Angk. } \\
\text { Sungai, } \\
\text { Danau \& } \\
\text { Penyebr. }\end{array}$ & 4,80 & Basis \\
\hline $\begin{array}{l}\text { 5. Angkutan } \\
\text { Udara }\end{array}$ & 1,06 & Basis \\
\hline $\begin{array}{l}\text { 6. Jasa } \\
\text { Penunjang } \\
\text { Angkutan }\end{array}$ & 2,58 & Basis \\
\hline b. Komunikasi & 0,18 & Non Basis \\
\hline $\begin{array}{l}\text { 8. KEUANGAN, } \\
\text { PERSEWAAN, \& } \\
\text { JS. PRSH. }\end{array}$ & 0,44 & Non Basis \\
\hline a. Bank & 0,41 & Non Basis \\
\hline $\begin{array}{l}\text { b. Lembaga } \\
\text { Keuangan tanpa } \\
\text { Bank }\end{array}$ & 0,18 & Non Basis \\
\hline $\begin{array}{l}\text { c. Jasa Penunjang } \\
\text { Keuangan }\end{array}$ & 0,02 & Non Basis \\
\hline d. Sewa Bangunan & 0,53 & Non Basis \\
\hline e. Jasa Perusahaan & 0,51 & Non Basis \\
\hline 9. JASA-JASA & 0,27 & Non Basis \\
\hline $\begin{array}{l}\text { a. Pemerintahan } \\
\text { Umum }\end{array}$ & 0,53 & Non Basis \\
\hline $\begin{array}{l}\text { 1. Adm. } \\
\text { Pemerintaha } \\
\mathrm{n} \& \\
\text { Pertahanan }\end{array}$ & 0,00 & Non Basis \\
\hline $\begin{array}{ll}\text { 2. Jasa } \\
\text { Pemerintah }\end{array}$ & 0,00 & Non Basis \\
\hline
\end{tabular}

\begin{tabular}{|c|c|c|}
\hline lainnya & & \\
\hline b. Swasta & 0,10 & Non Basis \\
\hline $\begin{array}{l}\text { 1. } \\
\text { Sosial } \\
\text { Kemasyaraka } \\
\text { tan }\end{array}$ & 0,10 & Non Basis \\
\hline 2. $\begin{array}{l}\text { Hiburan \& } \\
\text { Rekreasi }\end{array}$ & 0,07 & Non Basis \\
\hline 3. $\begin{array}{l}\text { Perorangan } \\
\text { \& } \\
\text { Rumahtangg } \\
\text { a }\end{array}$ & 0,11 & Non Basis \\
\hline $\begin{array}{l}\text { PRODUK DOMESTIK } \\
\text { REGIONAL BRUTO }\end{array}$ & $\mathbf{0 , 6 6}$ & Non Basis \\
\hline
\end{tabular}

Berdasarkan perhitungan LQ (Tabel 4.3)

Tahun 2015, maka secara rata-rata dapat diidentifikasikan sektor-sektor yang merupakan sektor basis (nilai LQ>1) adalah sektor Pertambangan dan Penggalian (dengan sub sektor basis : Minyak dan Gas Bumi dan Pertambangan Tanpa Migas dengan nilai LQ masing-masing sebesar 3,81 dan 10,12) dengan nilai LQ keseluruhan 5,95. Sektor Pertambangan dan Penggalian merupakan sektor yang memiliki keunggulan sehingga mampu memenuhi kebutuhan di dalam Provinsi Kalimantan Timur serta mempunyai potensi untuk diekspor ke daerah di luar Kalimantan Timur.

Sedangkan kedelapan sektor lainnya yaitu sektor Pertanian (0,58); Industri Pengolahan $(0,84)$; Listrik, Gas dan Air Bersih $(0,49)$; Bangunan (0,75); Perdagangan, Hotel dan Restoran (0,57); Pengangkutan dan Komunikasi $(0,66)$; Keuangan, Persewaan \& Jasa Perusahaan $(0,44)$; serta Jasa-jasa $(0,27)$ mempunyai nilai LQ lebih kecil dari satu sehingga dimasukkan sebagai sektor non basis di Provinsi Kalimantan Timur.

\subsubsection{Analisis Location Quotient (LQ) Kota/ Kabupaten Terhadap ProvinsiKalimantanTimur}

Hasil perhitungan nilai LQ diseluruh sektor perekonomian berdasarkan indikator pendapatan daerah yaitu PDRB atas dasar harga konstan 2000 apabila diambil rata-rata terdapat lima sektor yang menjadi basis perekonomian di masing-masing Kabupaten/Kota yang dapat diprioritaskan menjadi sektor unggulan pada 
tahun 2015 yaitu sektor Pertanian; Pertambangan \& Penggalian; Perdagangan, Hotel \& Restoran; Keu. Persewaan, \& Jasa Perusahaan; dan Sektor Jasa-Jasa, hal ini ditunjukkan dari hasil perhitungan nilai LQ sektor tersebut lebih dari satu. Hal ini menunjukkan bahwa sektor-sektor tersebut memiliki kontribusi yang besar dalam perekonomian dan pembangunan wilayah di Kabupaten/Kota masing-masing khususnya untuk Pemerintahan Provinsi Kalimantan Timur. Untuk lebih jelasnya hasil perhitungan analisis sektor basis perekonomian per Kabupaten/Kota terhadap Provinsi Kalimantan Timur periode 2016 dapat dilihat pada Tabel dibawah

Tabel 4.4 Nilai LQ Sektor-Sektor Perekonomian per Kabupaten/Kota Terhadap Provinsi Kalimantan Timur Berdasarkan Harga Konstan 2000 Tahun 2015/2016

\begin{tabular}{|c|c|c|c|c|c|c|c|c|c|c|}
\hline No. & SEKTOR & Paser & $\begin{array}{l}\text { Kutai } \\
\text { Barat }\end{array}$ & $\begin{array}{c}\text { Kutai } \\
\text { Kartanegara }\end{array}$ & $\begin{array}{l}\text { Kutai } \\
\text { Timur }\end{array}$ & Berau & $\begin{array}{c}\text { Penajam } \\
\text { Paser Utara }\end{array}$ & Ballikpapan & Samarinda & Bontang \\
\hline 1. & PERTANIAN & 2,42 & 2,78 & 1,48 & 0,63 & 2,74 & 2,75 & 0,55 & 0,32 & 0,03 \\
\hline 2. & $\begin{array}{l}\text { PERTAMBANGAN \& } \\
\text { PENGGALIAN }\end{array}$ & 1,70 & 1,21 & 1,69 & 1,97 & 1,35 & 0,85 & 0,00 & 0,19 & 0,00 \\
\hline 3. & INDUSTRI PENGOLAHAN & 0,06 & 0,10 & 0,11 & 0,01 & 0,34 & 0,89 & 1,27 & 0,86 & 4,00 \\
\hline 4. & $\begin{array}{l}\text { LISTRIK, GAS\& AIR } \\
\text { BERSIH }\end{array}$ & 0,51 & 0,61 & 0,33 & 0,15 & 0,22 & 0,63 & 2,80 & 3,25 & 0,22 \\
\hline 5. & BANGUNAN & 0,36 & 2,01 & 0,77 & 0,22 & 0,11 & 0,46 & 3,00 & 0,80 & 0,82 \\
\hline 6. & $\begin{array}{l}\text { PERDAGANGAN, HOTEL } \\
\text { \& RESTORAN }\end{array}$ & 0,27 & 0,70 & 0,49 & 0,38 & 0,87 & 1,49 & 2,50 & 2,60 & 0,24 \\
\hline 7. & $\begin{array}{l}\text { PENGANGKUTAN \& } \\
\text { KOMUNIKASI }\end{array}$ & 0,18 & 0,44 & 0,22 & 0,25 & 1,22 & 0,38 & 3,34 & 2,56 & 0,16 \\
\hline 8. & $\begin{array}{l}\text { KEUANGAN, } \\
\text { PERSEWAAN, \& IS. PRSH. }\end{array}$ & 0,49 & 0,84 & 0,35 & 0,26 & 0,15 & 1,24 & 1,22 & 4,90 & 0,28 \\
\hline 9. & JASA-JASA & 0,87 & 1,28 & 0,59 & 0,21 & 0,71 & 1,37 & 0,97 & 4,37 & 0,19 \\
\hline
\end{tabular}

Sumber : PDRB Provinsi Kalimantan Timur serta Masing-masing Kabupaten/Kota Terkait Tahun 2015-2016, Data diolah

Sektor pertanian dan sektor pertambangan dan penggalian adalah sektor yang mampu menjadi sektor basis dominan di beberapa Kabupaten/Kota di Provinsi Kalimantan Timur. Hal ini menunjukkan bahwa kedua sektor tersebut memiliki keunggulan kompetitif dan nilai kontribusi yang besar dalam perekonomian. Karena kedua sektor ini mampu bersaing dengan daerah kabupaten/kota lain yang ada di Provinsi Kalimantan Timur dengan mengekspor produk dari sektor basis ke luar pasar domestik, seperti hasil dari subsektor perkebunan yaitu hasil olahan kayu, crude palm oil dan industri pengolahan rotan. Kota/Kabupaten yang memiliki keunggulan kompetitif dibidang Pertanian antara lain Kabupaten Paser, Kutai Barat, Kutai Kartanegara, Berau dan Kabupaten Penajam Paser. Sementara sektor Pertambangan dan Penggalian menjadi keunggulan kompetitif di beberapa kabupaten/kota antara lain, Kabupaten Paser, Kutai Barat, Kutai Kartanegara, Kutai Timur, serta Kabupaten Berau.

\subsection{Analisis Klassen Provinsi Kalimantan Timur}

Metode Klassen Tipology digunakan untuk mengetahui pengelompokkan sektor ekonomi Provinsi Kalimantan Timur menurut struktur pertumbuhannya. Tabel dan gambar dibawah menyajikan hasil pengolahan data yang berupa perhitungan laju pertumbuhan dan kontribusi sektor PDRB Provinsi Kalimantan Timur Tahun 2015 -2016 dengan Migas. Pada Tabel dibawah terlihat bahwa sektor yang memiliki kontribusi rata-rata paling besar terhadap PDRB Provinsi Kalimantan Timur adalah sektor "Pertambangan dan Penggalian" $(42,38 \%)$; lalu diikuti sektor "Industri Pengolahan" (22,12\%). Untuk pertumbuhan ratarata, paling besar ditun-jukkan oleh sektor "Keuangan, Persewaan \& Jasa Perusahaan" (12,93\%); "Bangunan" (10,13\%); kemudian diikuti sektor "Jasa-Jasa" (8,25\%) dan "Pengangkutan dan Komunikasi" (7,56\%). Sedangkan sektor yang memiliki pertumbuhan rata-rata paling kecil, yaitu sektor "Pertambangan dan Penggalian".

Tabel 4.5 Laju Pertumbuhan dan Kontribusi Sektor PDRB Provinsi Kalimantan Timur Tahun 2015-2016 dengan Migas

\begin{tabular}{|c|c|c|c|c|c|}
\hline SEKTOR & $\begin{array}{c}\text { PER } \\
\text { BUI }\end{array}$ & $\begin{array}{l}\text { UM } \\
\mathbf{A N}\end{array}$ & KOI & $\begin{array}{l}\text { TRIB } \\
\text { II }\end{array}$ & $\begin{array}{c}\text { ANAL } \\
\text { ISIS } \\
\text { KLAS }\end{array}$ \\
\hline 1. Pertanian & $\begin{array}{l}4,6 \\
7 \%\end{array}$ & & & $\begin{array}{l}7,0 \\
0 \%\end{array}$ & $\begin{array}{l}\text { Berke } \\
\text { mban } \\
\mathrm{g}\end{array}$ \\
\hline $\begin{array}{l}2 . \\
\text { Pertambangan } \\
\text { \& Penggalian }\end{array}$ & & $\begin{array}{c}- \\
0,2 \\
3 \%\end{array}$ & $\begin{array}{c}42 \\
38 \\
\%\end{array}$ & & $\begin{array}{l}\text { Poten } \\
\text { sial }\end{array}$ \\
\hline
\end{tabular}




\begin{tabular}{|c|c|c|c|c|c|}
\hline $\begin{array}{l}\text { 3. Industri } \\
\text { Pengolahan }\end{array}$ & & $\begin{array}{c}- \\
3,9 \\
3 \%\end{array}$ & $\begin{array}{l}22 \\
12 \\
\%\end{array}$ & & $\begin{array}{l}\text { Potens } \\
\text { ial }\end{array}$ \\
\hline $\begin{array}{l}\text { 4. Listrik, Gas } \\
\text { \& Air Bersih }\end{array}$ & $\begin{array}{l}4,4 \\
7 \%\end{array}$ & & & $\begin{array}{l}0,3 \\
7 \%\end{array}$ & $\begin{array}{l}\text { Berke } \\
\text { mbang }\end{array}$ \\
\hline 5. Bangunan & $\begin{array}{l}10, \\
13 \\
\%\end{array}$ & & & $\begin{array}{l}4,7 \\
7 \%\end{array}$ & $\begin{array}{l}\text { Berke } \\
\text { mbang }\end{array}$ \\
\hline $\begin{array}{l}\text { 6. Perdag., } \\
\text { Hotel \& } \\
\text { Restoran }\end{array}$ & $\begin{array}{l}5,9 \\
3 \%\end{array}$ & & & $\begin{array}{l}10, \\
04 \\
\%\end{array}$ & $\begin{array}{l}\text { Berke } \\
\text { mbang }\end{array}$ \\
\hline $\begin{array}{l}7 . \\
\text { Pengangkutan } \\
\text { \& Komunikasi }\end{array}$ & $\begin{array}{l}7,5 \\
6 \%\end{array}$ & & & $\begin{array}{l}6,7 \\
6 \%\end{array}$ & $\begin{array}{l}\text { Berke } \\
\text { mbang }\end{array}$ \\
\hline $\begin{array}{l}\text { 8. Keu. } \\
\text { Persewaan, \& } \\
\text { Jasa } \\
\text { Perusahaan }\end{array}$ & $\begin{array}{l}12 \\
93 \\
\%\end{array}$ & & & $\begin{array}{l}4,1 \\
3 \%\end{array}$ & $\begin{array}{l}\text { Berke } \\
\text { mbang }\end{array}$ \\
\hline 9. Jasa-Jasa & $\begin{array}{l}8,2 \\
5 \%\end{array}$ & & & $\begin{array}{l}2,4 \\
3 \%\end{array}$ & $\begin{array}{l}\text { Berke } \\
\text { mbang }\end{array}$ \\
\hline Rata-Rata & \multicolumn{2}{|c|}{$1,59 \%$} & \multicolumn{2}{|c|}{$11,11 \%$} & \\
\hline
\end{tabular}

Sumber : PDRB Provinsi Kalimantan Timur dan PDB Nasional Tahun 2015-2016, Data diolah

Selanjutnya, melalui data pada tabel diatas, dapat diklasifikasikan sektor PDRB Provinsi Kalimantan Timur Tahun 2015-2016 dengan migas berdasarkan Tipologi Klassen sebagaimana tercantum pada gambar di bawah.

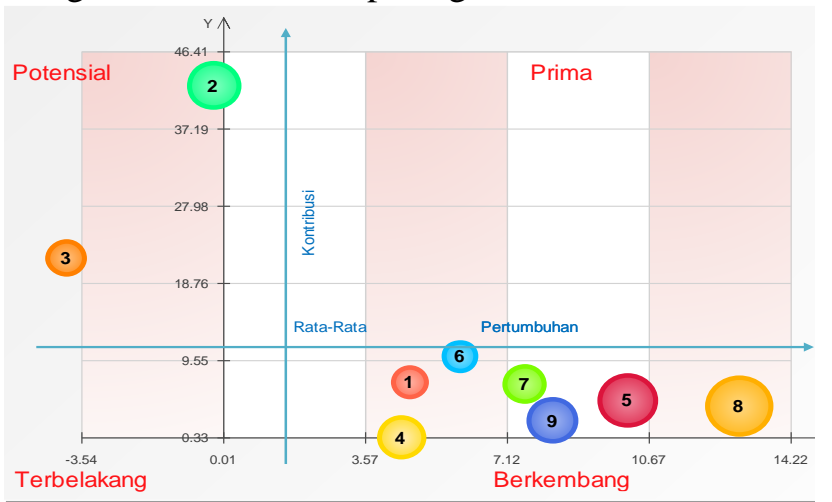

Sumber : PDRB Provinsi Kalimantan Timur dan PDB Nasional Tahun 2015-2016, Data diolah

Gambar 4.1 Klasifikasi Sektor PDRB Provinsi Kalimantan Timur Tahun 2015 2016 dengan Migas Berdasarkan Tipologi
Berdasarkan hasil analisis Klassen Tipology terhadap PDRB Provinsi Kalimantan Timur tahun 2015-2016 sebagaimana pada tabel 4.4 dan gambar 4.1, sektor yang dikategorikan sebagai sektor potensial, yaitu sektor yang mempunyai kontribusi rata-rata tinggi namun tertekan yaitu sektor "Pertambangan dan Penggalian" dan Industri Pengolahan.

\subsection{Analisis Gravitasi}

Analisis Gravitasi digunakan untuk mengetahui banyaknya interaksi yang bisa dilakukan oleh penduduk antar wilayah satu dengan wilayah lain. Dalam hal ini adalah kemampuan mengakses penduduk 10 kabupaten dan 3 kota di Provinsi Kalimantan Timur dengan penduduk Kota Samarinda selaku ibukota provinsi Kalimantan Timur atau sebaliknya.

Kemudahan kemampuan mengakses penduduk Kota dan Kabupaten di Provinsi Kalimantan Timur dengan penduduk Kota Samarinda atau sebaliknya, dapat memunculkan adanya perembesan kebawah (trickle down effect) dampak pembangunan maupun pertumbuhan ekonomi di kota pusat pertumbuhan ke wilayah yang ada di sekitarnya. Semakin besar nilai interaksi/nilai kemampuan mengakses, diharapkan memiliki pengaruh positif yang besar pula terhadap pembangunan dan pertumbuhan ekonomi di Kota dan Kabupaten di Provinsi Kalimantan Timur. Berikut perhitungan besarnya nilai aksesibilitas yang diharapkan antara penduduk Wilayah Kota Samarinda dengan Kota dan Kabupaten selain Kota Samarinda di Wilayah Provinsi Kalimantan Timur.

Tabel 4.6 Aksesibilitas Antara Wilayah Kota Samarinda dengan Kota dan Kabupaten di Wilayah Provinsi Kalimantan Timur 


\begin{tabular}{|c|c|c|c|c|}
\hline No & Kabupaten/Kota & $\begin{array}{c}\text { jumlah Penduduk } \\
\text { Th } 2000 \text { (jiwa) }\end{array}$ & $\begin{array}{c}\text { Jumlah Penduduk } \\
\text { Th } 2010 \text { (jiwa) }\end{array}$ & $\begin{array}{l}\text { Jarak da } \\
\text { Samarine }\end{array}$ \\
\hline 1 & Paser & 159.022 & 230.316 & 261 \\
\hline 2 & Kutai Barat & 135.960 & 165.091 & 33 \\
\hline 3 & Kutai Kartanegara & 427.791 & 626.680 & 31 \\
\hline 4 & Kutai Timur & 146.510 & 255.637 & $\overline{171}$ \\
\hline 5 & Berau & 117.769 & 179.079 & $54^{\circ}$ \\
\hline 6 & Malinau & 36.632 & 62.580 & $91^{1}$ \\
\hline 7 & Bulungan & 76.445 & 112.663 & $\overline{67:}$ \\
\hline 8 & Nunukan & 79.620 & 140.841 & 114 \\
\hline 9 & Penajam Paser Utara & 109.739 & 142.922 & 131 \\
\hline 10 & Tana Tidung & 6.592 & 15.202 & $81:$ \\
\hline 11 & Balikpapan & 409.023 & 557.579 & $\overline{111}$ \\
\hline 12 & Samarinda & 521.619 & 727.500 & $\overline{0}$ \\
\hline 13 & Tarakan & 116.995 & 193.370 & 74 \\
\hline 14 & Bontang & 99.617 & 143.683 & 101 \\
\hline
\end{tabular}

Sumber : Data Primer, diolah

Berdasarkan data tabel menunjukkan bahwa indeks gravitasi selama sepuluh tahun menunjukkan Kabupaten Kutai kartanegara di urutan pertama dibandingkan $13 \mathrm{kota} /$ kabupaten yang lain di Provinsi Kalimantan Timur. Nilai indeks gravitasi yang semakin meningkat menunjukkan semakin erat hubungan antar dua wilayah.

Aksesibilitas penduduk tertinggi terjadi antara penduduk Kota Samarinda dengan Kabupaten kutai kartanegara, diikuti dengan Kota Bontang, Balikpapan dan Penajam Paser Utara. Ini berarti bahwa frekuensi hubungan sosial, ekonomi transfer pengetahuan dan sejenisnya antara kedua kota/kabupaten tersebut dengan Kota Samarinda tertinggi dibandingkan dengan Kota/kabupaten lainnya. Sedangkan kemampuan aksesibilitas pendudukterendah terjadi antara penduduk Kota Samarinda dengan Kabupaten Tana Tidung.

\subsection{Analytical Hierarchy Process (AHP) Provinsi Kalimantan Timur}

\subsubsection{Analisis Bobot Aspek Penunjang Industri dan Investasi}

Analisis terhadap keseluruhan data yang dihimpun dilakukan berdasarkan variabel yang telah ditetapkan. Oleh karena itu, untuk menentukan jenis potensi investasi/potensi unggulan daerah yang cukup feasible dikembangkan, masing-masing potensi unggulan dianalisis dengan metode Analytical Hierarchy Process.

Hasil dari pembobotan dapat dilihat pada gambar berikut :

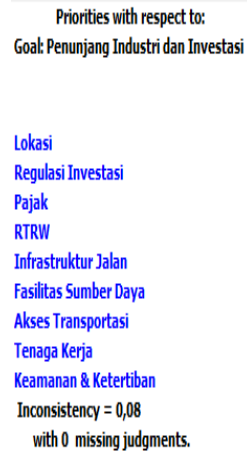

Gambar 4.2Output Sintesis

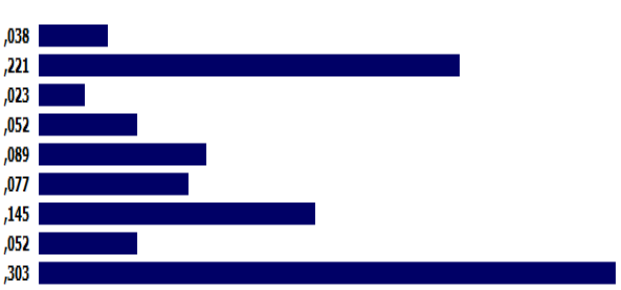

\footnotetext{
Priorities with respect to:

Goal: Penunjang Industri dan Investasi
}

Keamanan \& Ketertiban
Regulasi Investasi
Akses Transportasi
Infrastruktur Jalan
Fasilitas Sumber Daya
RTRW
Tenaga Kerja
Lokasi
Pajak
Inconsistency = 0,08
with0 missing judgments.

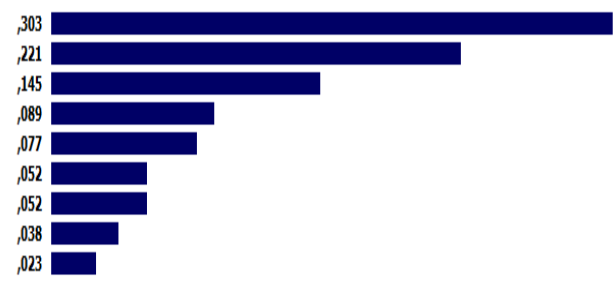

\section{Gambar 4.30utput Sintesis Setelah diurutkan}

\section{Sumber : Data Primer, diolah}

\subsubsection{Pengembangan Kawasan Unggulan Berdasarkan Pendekatan Cluster}

Terdapat 8 (delapan) jenis klaster kawasan industri di Provinsi Kalimantan Timur yang hingga saat ini terus dibangun dan dikembangkan untuk mendukung upaya percepatan transformasi ekonomi. Pendekatan klaster disini didefinisikan sebagai pemusatan industri pada bidang spesifik tertentu atau lembaga terkait yang secara lokasi berdekatan, yang dihubungkan oleh kesamaan dan kebutuhan untuk saling melengkapi. Menurut Porter (2008), pendekatan klaster merupakan kunci bagi pertumbuhan ekonomi, dengan karakteristik 
yaitu : (1) Pemusatan industri dalam suatu wilayah; (2) Memiliki kesamaan teknologi, keterampilan dan sistem pen-danaan; (3) Memiliki ciri khas dalam keterkaitan pembelipenyedia; dan (4) Me-ngembangkan keunikan yang sulit ditiru. Terobosan pembangunan kawasan-kawasan industri berdimensi kewilayahan di Kalimantan Timur juga dilakukan selaras dengan Perpres 32 Tahun 2011 tentang Masterplan Percepatan dan Perluasan Pembangunan Ekonomi Indonesia (MP3EI). Adapun 8 (delapan) kawasan industri yang dimaksud adalah sebagai berikut:

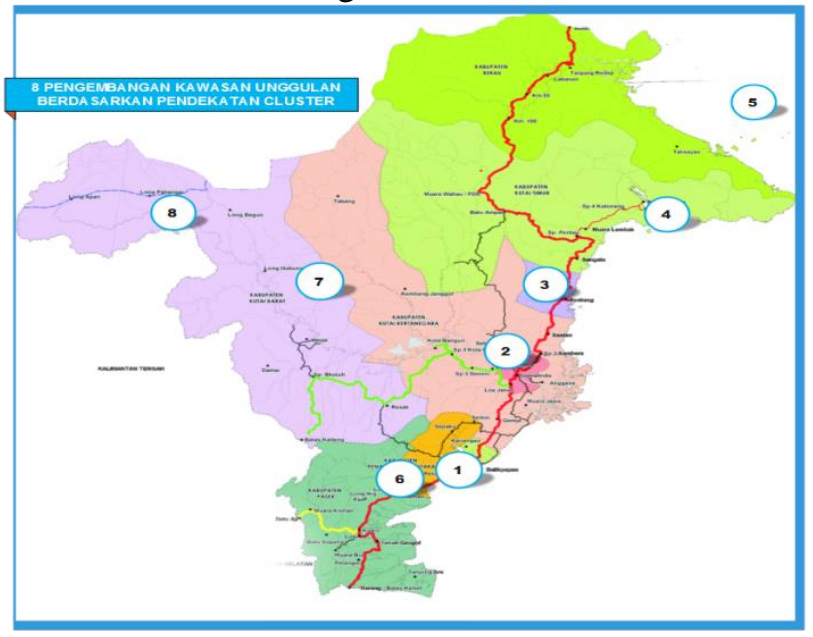

Gambar 4.2 Pengembangan Kawasan Unggulan Berdasarkan Pendekatan Cluster

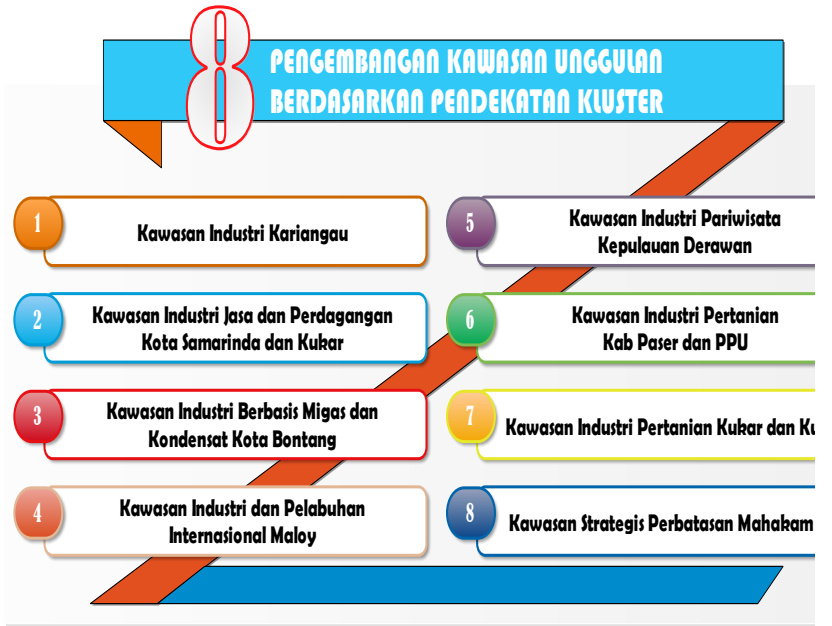

\section{KESIMPULAN}

Kesimpulan yang dapat pada penelitian ini adalah :
1. Kompetensi Inti Industri Daerah (KIID) dan komuditas unggulan bersarkan data paparan Kepala Disperindagkop Provinsi Kalimantan Timur dalam Rakor Bapeda se-Kalimantan Timur 2015 adalah,

a. Kompetensi Inti Industri Daerah (KIID) : industri produk pengolahan ikan, rumput laut, gula merah,singkong menjadi bioethanol, industri tenun, dan insdustri pariwisata.

b. Komoditas Unggulan : perikanan, batubara, minyak bumi, kelapa sawit, singkong, karet, sarung tenun, durian, dan pariwisata.

2. Hasil perhitungan LQ Tahun 2016, maka secara rata-rata dapat diidentifikasikan sektor-sektor yang merupakan sektor basis (nilai LQ>1) adalah sektor Pertambangan dan Penggalian (dengan sub sektor basis : Minyak dan Gas Bumi dan Pertambangan Tanpa Migas dengan nilai LQ masingmasing sebesar 3,81 dan 10,12) dengan nilai LQ keseluruhan 5,95. Sektor Pertambangan dan Penggalian merupakan sektor yang memiliki keunggulan sehingga mampu memenuhi kebutuhan di dalam Provinsi Kalimantan Timur serta mempunyai potensi untuk diekspor ke daerah di luar Kalimantan Timur. Sektor pertanian dan sektor pertambangan dan penggalian adalah sektor yang mampu menjadi sektor basis dominan di beberapa Kabupaten/Kota di Provinsi Kalimantan Timur. Hal ini menunjukkan bahwa kedua sektor tersebut memiliki keunggulan kompetitif dan nilai kontribusi yang besar dalam perekonomian.

3. Hasil analisis Klassen Tipology terhadap PDRB Provinsi Kalimantan Timur tahun 2015-2016 sektor yang dikategorikan sebagai sektor potensial, yaitu sektor yang mempunyai kontribusi rata-rata tinggi namun tertekan yaitu sektor "Pertambangan dan Penggalian" dan Industri Pengolahan. Pembangunan ekonomi dengan mengacu pada kedua sektor tersebut selain berdampak pada percepatan pertumbuhan ekonomi juga akan berpengaruh pada perubahan mendasar dalam struktur ekonomi. Sektor 
"Pertanian", "Listrik, Gas dan Air Bersih", "Bangunan", Perdag. Hotel dan Restoran", Pengangkutan dan Komunikasi", Keuangan Persewaan, dan Jasa Perusahaan", dan "Jasa-Jasa" termasuk ke dalam sektor berkembang, Sementara sektor-sektor yang tergolong ke dalam sektor prima dan terbelakang tidak memiliki kontribusi dan nilai pertumbuhan

\subsection{Saran}

Kerangka Pikir Bangun Industri Provinsi tahun 2015-2035 harus mencakup:

1. Industri Andalan, yaitu industri prioritas yang berperan besar sebagai penggerak utama (prime mover) perekonomian di masa yang akan datang. Selain memperhatikan potensi sumber daya alam sebagai sumber keunggulan komparatif, industri andalan tersebut memiliki keunggulan kompetitif yang mengandalkan sumber daya manusia yang berpengetahuan dan terampil, serta ilmu pengetahuan dan teknologi.

2. Industri Pendukung, yaitu industri prioritas yang berperan sebagai faktor pemungkin (enabler) bagi pengembangan industri andalan secara efektif, efisien, integratif dan komprehensif.

3. Komoditas andalan, yaitu komoditas yang merupakan bahan baku atau bahan dasar bagi industri andalan yang berupa komoditas unggulan.

4. Modal Dasar, yaitu faktor sumber daya yang digunakan dalam kegiatan industri untuk menghasilkan barang dan jasa serta dalam penciptaan nilai tambah atau manfaat yang tinggi.

\section{DAFTAR PUSTAKA}

$\begin{array}{crrr}\text { Brodjonegoro, Bambang } & \text { Permadi } & \text { dan } \\ \text { Bey Sapta } & \text { Utama. } & 1992 . \\ \text { "AHP:Analytic } & & \text { Hierarchy } \\ \text { Process", } & \text { Pusat } & \text { Antar } \\ \text { Universitas-Studi } & & \\ \text { Ekonomi,Universitas Indonesia. }\end{array}$

Richard L. Daft, 2010. Era Baru Manajemen. Edward Tanujaya, Edisi 9,Salemba Empat.
Sjafrizal, 1997. "Pertumbuhan Ekonomi Dan Ketimpangan Regional Wilayah Indonesia Bagian Barat". Prisma, No.3. Hal:27-38

Sjafrizal, 2008. Ekonomi Regional, Teori dan Aplikasi (cetakan pertama). Padang: Baduose Media.

Stillwell, John and Clarke, Graham. (2004) Applied GIS and Spatial Analisys. England: John Wiley \&Sons.

Saaty, T. L (1983), Decision Making For Leaders: The Analytical Hierarchy Process for Decision in Complex World. RWS Publication, Pittsburgh.

Tarigan, Robinson. 2004. Ekonomi Regional. Jakarta: Bumi Aksara.

Tarigan, Robinson. 2006. Perencanaan pembangunan wilayah. Jakarta: Bumi Aksara.

Umar, Husein, 2000, Studi Kelayakan Bisnis - Manajemen Metode dan Kasus, Cetakan ke Empat, PT. Gramedia, Jakarta

Warpani, Suwardjoko. 2001. Analisis Kota dan Daerah, Penerbit ITB, Bandung 
